Araştırma Makalesi

\title{
Evrensel Tasarım İlkelerinin Mayınlı Alanı: Dijital Haritalar ve Gazetecilik
}

\author{
Bilge Narin (Arş. Gör. Dr.) \\ Gazi Üniversitesi İletişim Fakültesi \\ narinbilge@gmail.com
}

Başvuru Tarihi: 09.05.2018

Yayına Kabul Tarihi: 13.07.2018

Yayınlanma Tarihi: 30.07.2018

\section{Öz}

Haritalar mekânsal bir içeriğe sahip haberleri aktarmanın etkili bir yolu olarak en eski haber anlatı türlerinden olsa da iletişim araştırmalarında ihmal edilen bir alan olarak karşımıza çıkmaktadır. Öte yandan haberin dijital platformlara taşınması ve web teknolojilerindeki gelişmeler ile birlikte, haber haritacılığı yeni bir evreye girmiştir. Büyük veri setlerinin ortaya çıkması dijital haritacılığın popülerleşmesine neden olurken, gazetecilerin öz yeteneklerine kartografinin de eklenmesini gerekli kılmıștır. Bu araștırmada, alandaki eksikliği gidermek amacıyla öncelikle gazetelerdeki harita anlatılarıyla ilgili sınırlı sayıdaki araștırmanın bulguları özetlenmiştir. Ardından, dijital harita anlatıları yeni teknolojik olanaklar bağlamında değerlendirilmiştir. Çalışmanın son bölümünde, Türkiye'de çok tıklanan çevrimiçi gazetelerde yer verilen dijital haritalarda evrensel tasarım ilkelerinin web erişilebilirliği bağlamında ne derece önemsendiği sorgulanmıştır. Örneklem 16 Nisan 2017 Anayasa değişikliği referandumuyla ilgili dijital haber haritaları ile sınırlı tutulmuştur. Araştırma sonucunda dezavantajlı grupların enformasyona erişimini kolaylaștırması beklenen teknolojik özelliklerin, dijital haritaların tasarım ve içeriklerinde yeterince kullanılmadığı saptanmıştır.

Anahtar Kelimeler: dijital kartografya, evrensel tasarım ilkeleri, harita, internet gazeteciliği. 
Research Article

\title{
A Minefield of the Principles Of Universal Design: Digital Maps and Journalism
}

\author{
Bilge Narin (Res. Asst. Dr.) \\ Gazi University Faculty of Communication \\ narinbilge@gmail.com
}

Date Received: 09.05.2018

Date Accepted: 13.07.2018

Date Published: 30.07.2018

\begin{abstract}
Even though maps are one of the oldest types of news storytelling as an effective way to transfer news with spatial content, it is a neglected topic in communication studies. On the other hand, news mapping has entered a new stage with the news on digital platforms and developments in web technologies. While the emergence of large data sets has led to the popularization of digital cartography, journalists need to add cartography to their professional competency. In this study, firstly, the findings of a limited number of studies on maps in newspapers are summarized. Then, digital map stories are evaluated in the context of new technological possibilities. In the last part of the study, the importance of the principles of universal design in the context of web accessibility is questioned with the sample of the digital maps on the most clicked online newspapers in Turkey. The sample is limited to the digital news maps that are related to the Turkish constitutional referendum on 16th April 2017. As a result of the research, it has been determined that the technological features expected to facilitate access to information by disadvantaged groups are not sufficiently used in the design and contents of the digital maps.
\end{abstract}

Keywords: digital cartography, the principles of universal design, map, internet journalism. 


\section{Giriş}

Mekânı temsil eden bir öğe olarak haritalar coğrafi, demografik ve jeopolitik bilgi kaynaklarındandır. Gazeteler ise haritaları kamuoyu ile buluşturan belli başlı medya ve iletişim araçlarındandır. Özellikle coğrafya temelli iklim, trafik, göç, seçim, terör olayları ve uluslararası ilişkiler gibi mekânsal karşılaştırma içeren haber konularında haritalar anlatımı güçlendiren haber unsurlarıdır. Öte yandan çevrimiçi haberlerde kullanılan dijital haritalar, web tabanlı haritacılık araçlarının her yerden erişilebilirliği ve kullanım kolaylığı nedeniyle popülerliğini giderek arttırmaktadır.

Web haritacılığı ve harita sunucu teknolojilerindeki yenilikler büyük ölçüde gelişmiş ve haritaları haber raporuna dönüştürmek için yeni olanaklar sunmuş olsa da (Holmberg ve Foote, 2008, 323), web tabanlı haritacılığın gazetecilik pratiklerini nasıl etkilediği ihmal edilen bir alan olarak karşımıza çıkmaktadır. İletişim odaklı geleneksel medya metin analizlerinde baskın bir biçimde yazılı metin, sabit metin (fotoğraf) ve hareketli metin (video) üzerine odaklanılırken, yeni dijital anlatı türlerini merkeze alan çalışmaların da genellikle bu anlatılarla sinırlandırıldığı görülmektedir. Son dönemde yaygınlık kazanan veri gazeteciliği ve veri görselleştirme çalışmalarıyla gelişen dijital kartografya ve habercilik çalışılmayı bekleyen bir alan olarak karşımıza çıkmaktadır. Başka bir anlatımla, gerek geleneksel medyayı gerekse dijital medyayı konu alan iletişim araştırmalarında medya metinleri, fotoğraf ve videolar egemen araştırma nesneleri olurken; gazetelerde yer alan haritalar ise yeterince ilgi görmemektedir.

Hangi belirli dijital harita türlerinin çevrimiçi gazetelerde sıklıkla kullanıldığı, bu tercihlerin altına yatan etmenler, baskın ideolojilerin yeniden üretildiği bir dijital anlatı olarak haritalar, harita üretiminde görev alan tasarımcı ve grafikerlerin çalışma koşulları, bu alanda çalışacak meslek profesyonellerinin ihtiyaç duyduğu temel beceriler, kullanıcıların coğrafi okuryazarlık düzeyleri, harita içeriklerinde nelerin ne sıklıkla hangi amaçla sunulduğu ile basılı ve çevrimiçi gazetelerde kullanılan haritaların benzerlikve farklılıkları gibi araștırma konuları gerekuluslararası yazında gerekse Türkiye'de çalışılmayı bekleyen alanlar olarak karşımıza çıkmaktadır. Özetle gazetelerde harita üretimi, haritalardaki anlatılar ve harita okurlarına odaklanan çalışmalara ihtiyaç duyulmaktadır.

Alandaki eksiklikten hareketle, bu araştırmada Türkiye'de en çok tıklanan çevrimiçi gazetelerin 16 Nisan 2017 Anayasa Değişikliği Referandumunda kullandıkları dijital haritalar, evrensel tasarım ilkelerine uygunlukları kapsamında incelenmiștir. İlk kez mimarlık alanında kullanılan evrensel tasarım ilkeleri yaşlılar, engelliler ve öğrenme güçlüğü bulunan kimseler gibi dezavantajlı kişi ve grupların kullanım pratiklerindeki sorunları konu edinerek çözüm yolları arayan bir yaklaşımdır (Mace, 1985). Daha geniş anlamıla evrensel tasarım, mümkün olan en büyük ölçüde adaptasyon gerektirmeksizin, her yaştan ve yetenekten insan tarafından kullanılabilecek ve deneyimlenebilecek ürünlerin ve ortamların tasarımı olarak tanımlanmaktadır (Center for Accessible Housing, 1995).

Çalışmada harita ve gazetecilik ile ilgili önceki araştırmaların bulgularının özetlenmesinin ardından internet teknolojilerinin getirdiği olanaklar kapsamında çevrimiçi haritanın özellikleri serimlenmiştir. Çalışmanın son bölümünde ise referandum sonuçlarına ilişkin dijital haritalar evrensel tasarım ilkelerine 
uygunlukları açısından değerlendirilmiştir. Haritaların üretim aşaması ve okurlar tarafından alımlanması araştırma kapsamı dıșında bırakılmıştır.

\section{Önceki Araştırmaların Bulguları}

Haritalar güçlü görüntüler sağlar. Dünyayı nasıl düşündüğümüzü değiștirmek isteyen insanlar için, dünya haritamızı değiştirmek sıklıkla gerekli ilk adımdır. Statükoyu savunanlar için de haritalar aynı derecede öneme sahiptir (Dorling ve Fairbairn, 1997, 154). Bu bağlamda habercilik ve haritacılık konusunu ele alan çalışmaların önemli bir bölümünde haritalar hâkim ideolojinin taşıyıcısı olarak görülerek (Monmonier, 2005; Batuman, 2010; Medzini, 2017); kamuoyunun ülke dışı, ülke içi ve yerel konularla ilgili algısını etkilediği vurgulanmaktadır (Vujakovic, 2002, 188). Bir başka anlatımla, eleștirel kartografi çalışmaları kartografların öznelliğini ve ürettikleri haritalarda kendi dünya görüşlerini ve sosyo-kültürel değerlerini temsil etmekten kaçınamayacaklarını vurgulamaktadır. Çünkü haritalardaki adlandırma, ölçeklendirme, kesim noktaları ve hatta renklendirme/ gölgelendirme seçenekleri bilinçli ya da bilinçsiz olarak seçici bir gerçeklik sunulmasına neden olmaktadır (Harley, 1998).

Monmonier (1989), gazetecilikte kullanılan haritalar ile ilgili çalışmasında, kamuoyunun jeopolitik konulardaki anlayışı ile kitle medyası haritacılığı arasında doğrudan bağlantı olduğunu söylemektedir. Ona göre, haber medyası toplumun en belirgin kartografik eşik bekçisi ve bu nedenle de coğrafi eğitimcisidir.

Basılı gazeteler ile onların çevrimiçi sürümlerinde yer alan haritaların karşılaștırıldı̆̆ı bir başka çalışmada, yedi büyük Amerikan gazetesi incelenmiștir. Araștırma sonucunda çevrimiçi sürümlerde dijital haritalarda etkileşim ve multimedya özelliklerinin yaygın biçimde kullanılmadığı ve çevrimiçi haritaların anlatılan haber metinleriyle iyi bir şekilde bütünleşemediği bulgulanmıştır. Gazete çalışanlarıyla yapılan görüşmelerde ise, personel eksikliği ve zaman baskısı nedeniyle basılı ve çevrimiçi sürümler arasındaki üretim ayrımının çoğu kez daha nitelikli haritaların ortaya çıkmasını engellediği ifade edilmiştir (Holmberg ve Foote, 2008).

Türkiye'deki haber kanallarında harita kullanımının değerlendirildiği bir araştırmada ise, 2013 yılında yedi günlük zaman dilimi içerisinde beş haber kanalında 17.0024.00 saatleri arasında yayınlanan haritalar incelenmiştir. Araștırma sonunda 830 haberden yalnızca 127'sinde haritaya yer verildiği; bu haberlerin \%80'inin de hava ve yol durumu olduğu sonucuna varılmıștır (Demirci ve Barut, 2015).

Özetleyecek olursak, harita anlatılarının ideolojik yanlılığı, dijital haber haritalarında teknolojik yeniliklerin kullanım sıklığı ile hangi haber anlatılarında haritaların yaygın biçimde kullanıldığı gibi konular gazetecilik ve haritalar ilgili sınırlı sayıdaki araştırmanın ilgi alanını oluşturmaktadır. Haritaların evrensel tasarım ilkeleri ve web erişilebilirliğine uygunluğunu sorgulayan bir çalışma ise bulunmamaktadır.

\section{Yeni Teknolojik Olanaklar Ekseninde Çevrimiçi Harita}

Bugün kullandığımız dijital haritalar çeşitli özelliklerle geçmişteki geleneksel basılı haritalardan farklıdır. İnternetin yaygınlaşmasından önce seri üretim ve tüketimle karakterize olan haritalar, yeni iletişim teknolojileri ile birlikte daha kolay üretilebilir hale gelerek yaygınlaşmış, kişiselleştirme özelliklerinin eklenmesi ile dinamik bir hale gelmiştir. Ayrıca dijital haritalar fotoğraf veya diğer infografik öğelerle de bütünleşmiştir. 
Dijital haritalama hizmetleri, 1996 yılında MapQuest'in geliștirilmesinden başlayarak (Geller, 2007) kamusal alana taşınmış, 2005 yılında Google Haritalar, Yahoo! Haritalar ile patlama yaşayarak istikrarlı bir biçimde gelişimini sürdürmüştür. $\mathrm{Bu}$ gelişmelerle birlikte dijital haritaların özellikle yol bulma amacıyla sıradan insanların gündelik yaşamına girmesi mümkün hale gelmiştir. Açık kaynak kodlu harita hizmetlerinin erişilebilirliği, profesyonel olmayan kişilerin de alternatif haritalama uygulamalarını geliştirmelerine ön ayak olmuştur (Luchetta, 2017, 4). Günümüzde Alibaba, Google, HERE, Michello ve NavInfo küresel dijital harita pazarının önde gelen tedarikçileri kabul edilmektedir (Global Digital Map Market Report 2017-2021, 2017). Google Maps, Microsoft Bing Maps, OpenLayers, Foursquare, OpenStreetMap, MapQuest, Mapbox, CartoDB, Esri ArcGIS ve Yahoo BOSS PlaceFinder ise popüler haritalama uygulamalarındandır (Wagner, 2015).

2012 yılında aylık tekil bir milyar kullanıcıya ulaşan Google Maps ve Google Earth (O’Beirne, 2016), şu anda dünyanın en yaygın kartografik bilgi kaynağı konumundadır. ABD merkezli bir şirket olan Google, sınır çizgilerinin işaretlenmesi ve yer isimlerinin etiketlenmesi ile ilgili karar almada özerkliğe sahiptir. Google ve benzeri şirketlerin haritacılık alanına giriși, harita ile üretilen güç ilişkilerinde de yeni bir dönüm noktası olmuştur. Google'ın kartografik teknolojisi ülkelere, kuruluşlara veya paydaşlara haritalara bilgi ekleme olanağı sunarken; onların dijital haritaları politik propaganda için bir platform olarak kullanmalarına zemin hazırlamaktadır. Böylelikle, dijital haritalar, toprak anlaşmazlıkları bulunan taraflar arasında yeni bir savaş arenası haline gelmekte ve her bir taraf kendi bakış açısıyla uyumlu haritalar üretmektedir (Quiquivix, 2014). Bu kapsamda, dijital haritacılık endüstrisinin sahiplik yapısı ve kartografik ekonomi politik merkezli eleştirel haritacılık çalışmalarına ihtiyaç duyulmaktadır.

Coğrafi Bilgi Sistemleri (CBS), Uzaktan Algılama, Google Maps, Google Earth ve diğer konumsal tabanlı sistemlerden verilerin kolayca elde edilerek kullanılabilmesi, medya sektöründe de harita anlatılarının hazırlanması ve sunumu açısından yeni olanaklar sağlamıştır (Demirci ve Barut, 2015, 17-18). Dijital haritalar sürekli olarak biriken büyük hacimdeki dijital verilerden elden bilgiyi özetlemek ve iletmek için etkili bir haber anlatısı olarak kabul edilmektedir. Gazetecilikte veri güdümlü hikaye anlatımı uygulamaları ve jeogörsel analizler, harita hikayeciliği (story maps) ile multi-tematik atlasların yaygınlaşmasına neden olmuştur. Coğrafi görsel analizler, kullanıcıların konum bazlı verileri keşfetmesine, kalıpları tespit etmesine ve gelecekteki sonuçları tahmin etmesine olanak tanıyan etkileşimli haritalama sistemleri geliştirmektedir (Berendsen ve diğerleri, 2018, 1-3).

Katılımcı ve kitle kaynakla toplanan verilere dayalı gazeteciliğin getirdiği yenilikler de coğrafi-mekânsal enformasyon üretiminde bir başka boyut olarak karşımıza çıkmaktadır. Medya profesyonelleri zaman zaman kullanıcıların sağladığı verilerin güvenilirliğini sağlama ve veri kalitesi konularında sorunlar yaşasa da, gelișen dijital teknolojiler kitle kaynaklı dijital haritalama için yeni firsatlar sunmaktadır. Amatör kullanıcılardan elde edilen veriler, resmi verilerin hem alternatifi hem de tamamlayıcısı olarak gazeteciler tarafından kullanılmaktadır.

Özellikle doğal afetlerde kullanıcılar tarafından gönüllü olarak eş zamanlı sağlanan konum bazlı veriler, internet gazeteciliğinde işbirlikçi bilgi üretimi açısından 
yaratıcı sonuçlar doğurmaktadır (Schimak ve diğerleri, 2015). Trafik haberleri de kitle kaynak verilerle haritalandırılabilmektedir. Örneğin Waze, dünyanın popüler topluluk tabanlı trafik ve navigasyon uygulamalarından biridir.

Teknolojik gelişmelerle, dijital haritalar tamamlanmış birer anlatı olmaktan çok giderek bir deneyimleme haline gelmektedir (Dodge, Kitchin ve Perkins, 2009, 12; Salovaara, 2016). Ücretsiz, etkileşimli, kolay erişilip paylaşılabilir ve kişiselleştirilebilir haritalar internet ortamının temel anlatı türlerinden biri olarak karşımıza çıkmaktadır.

\section{Gazeteciler için Elverişli Haritacılık Araçları}

Haber odalarında internet gazetecilerinin haberlerini zenginleştirebilecekleri dijital haritalar için geliştirilmiş, farklı hikâyeleştirme tarzlarına sahip çok sayıda araç kullanılmaktadır. Bazı haritalar canlı URL'lerde bulunmakta ve olaylar, koşullar, bağlamlar ve gerçekler değişip geliştikçe gerçek zamanlı olarak güncellenebilmektedir. Levin (2016) gazetecilerin kullanabileceği bu haritacılık araçlarından bazılarını ve temel özelliklerini şöyle sıralamıştır:

Google My Maps: Bu araç, gazetecilerin kullandığı en bilinen uygulamalardan biridir. Pimler, katmanlar, metinler ve fotoğraflar ile kișiselleștirilebilir hale getirilen verilerle Google harita oluşturulabilir.

Story Maps: Bu platform, kullanıcıların haritalarına görüntü ve video gibi özelliklere ek olarak ses eklemelerini sağlamaktadır.

Story Map Cascade: Benzer araçların aksine, bu araç yatay yerine dikey harita hikayeleştirmeleri yapılabilmesine olanak verir. Metin, resim, üç boyutlu görüntüler ve videolar içerebilir.

Open Heat Map: Hava durumu haberlerinde kullanılan 1sı haritalarındandır. Verilere dayalı olarak haritanın farklı kısımlarını boyayarak, sayılara renk atamaktadır. Böylece, okurlar kolaylıkla verilerin temsil ettiği eğilimleri ve kavramları anlamlandırabilmektedir.

Google Crisis Map: Devam eden bir krizi haberleştirirken kullanılan bir araçtır. Doğal afetler, tehlikeler ve acil durum hazırlıklarında işlevseldir.

\footnotetext{
MapHub: Google Haritalar'ın bir alternatifi olarak, MapHub etkileşimli haritalar oluşturmak için başka bir platform sunmaktadır. Google Haritalar uygulamasında harita altlıkları sınırlıyken, bu araç farklı harita altığı seçenekleri sunmaktadır.

VIS (Visual Investigative Scenarios): Araştırmacı gazetecilere, aktivistlere ve diğer kullanıcılara karmaşık iş veya suç şebekelerini haritalamada yardımcı olmak için tasarlanmış bir veri görselleştirme platformudur.
}

Yeni konum merkezli veri tabanı teknolojileri, gazetecilerin coğrafi bilgileri daha etkili biçimde kullanmalarına ve kolaylıkla yeni dijital harita türleri oluşturmalarına yardımcı olmaktadır. Tüm bu araçlar başlangıçta etkili ve hızlı birer coğrafi görsel anlatı oluşturulmasını kolaylaştıran teknolojiler olarak karşımıza çıkmaktadır. Ancak bu teknolojiler, bir yandan gazetecinin sahip olması gereken mesleki becerilere yenilerinin eklenmesine neden olurken, öte yandan okurların eleştirel coğrafi okuryazarlık becerilerinin de geliştirilmesini gerekli kılmaktadır.

D’Ignazio (2017, 12) öğrenci-merkezli coğrafi veri okuryazarlığı geliştirmek için, geliştirilen araçların hangi özelliklerinin gerçekten gerekli ve öğrenilmeye değer olduğuna, veri güvenliği açısından sorun yaratıp yaratmadıklarına ilişkin eleştirel bir okuma yapılması gerektiğini vurgulamaktadır. Günümüzde çıktı (output focused) 
odaklı veri araçları yerine kullanıcı ya da öğrenenlere odaklanan (learner focused) veri araçları önem kazanmaktadır (D’Ignazio ve Bahargava, 2016). Öte yandan haritacılık sanatı ve bilimi, gelişimini insanlık için önemli olan sorunlara ve sürdürülebilirliğe dayandırılan işlere odaklamak zorundadır (Robinson ve diğerleri, 2017, 32). Bu kapsamda, toplumun tüm kesimlerinin rahatça erişebildiği ve zorlanmadan okuyup anlamlandırabildiği dijital harita haberlerinin de oluşturulması gerekmektedir. Özetle, kullanıcı pratiklerini daha çok önceleyen, evrensel tasarıma uygun dijital habercilik pratiklerine ihtiyaç duyulmaktadır.

\section{Evrensel Tasarım IIlkeleri ve Web Erişilebilirliği}

Dijital haritalar, etkileşimli ve doğru biçimde tasarlandıklarında büyük veri analizleri için güçlü birer görsel anlatı sağlamaktadır. Doğru tasarlanmış etkileşimli bir haritada kullanıcılar coğrafi veri kaynaklarını kullanarak diğer veriler arasında gezinebilir, arama yapabilir, veri setlerini filtreleyebilir ve karşılaştırabilirler (Robinson ve diğerleri, 2017, 35). Anlaşılacağı üzere dijital haritalar yeni çok sayıda özellik sunsa da bu özellikler çoğunlukla eksik ya da yanlış kullanılmaktadır. Esasen tüm bu teknolojilerin amacı evrensel tasarım ilkelerine uygunluğu arttırarak, dezavantajlı kişi ve grupların internete erişim meselesini kolaylaştırmak olmalıdır.

Evrensel tasarım ilkeleri en basit haliyle her insanın kullanabildiği ürün veya ortam tasarımı olarak tanımlamıştır. Evrensel tasarıma uygun ürün ve ortamların adaptasyon ve özel tasarım ihtiyacı olmaksızın, tüm insanlar tarafından mümkün olan en geniş ölçüde kullanılabilmesi gerekmektedir (Mace, 1991). Yani mevcut tasarımın dezavantajlı grupları ayrıştırıcı değil, kapsayıcı olması önerilmektedir. Böylece engelliler, yaşlılar ve çocuklar gibi toplumun çoğu kez dışlanan kesimleri de bu tasarımlardan rahatlıkla ve ayrımcılığa uğramadan yararlanabileceklerdir.

Web erişilebilirliği ise evrensel tasarım ilkelerinin internet ortamındaki karşılığı olarak; sanal ortamda engellileri, çocukları ve yaşlıları da kapsayacak şekilde herkesin algılayabileceği, anlayabileceği, gezinebileceği ve etkili bir şekilde kullanabileceği içerikler oluşturulması anlamına gelmektedir (Brittain, 1995; Paciello, 1996; Berners-Lee, 1997). Ayrıca, kullanıcıların da aktif biçimde yaratma ve dağıtma aşamalarına katkıda bulunabilecekleri bir içerik oluşturulması son derece önemlidir.

Düşük bağlantı hızı gibi teknik faktörler enformasyona erişimi engelleyebilirken, kötü tasarlanmış Web siteleri de kullanıcıların amaçlanan bilgilere erişmesini zorlaştırmaktadır (Kirsner, 1997). Başka bir anlatımla, web erişilebilirliği yalnızca araca ya da teknolojiye sahip olmanın dijital uçurumu ortadan kaldırmadığını vurgulayarak; içerik ve tasarımın da erişimi engelleyebileceğini ortaya koyan makro bir yaklaşımdır .

World Wide Web'in herkes için erişilebilirliği, başlangıcından bu yana önemli kabul edilen konulardan olagelmektedir. Dünya çağında ağın mucidi Tim Berners-Lee, 1997 yılında World Wide Web Erişilebilirlik Girişimi'ni başlatarak; konunun önemini şu sözlerle açıklamıştır: "Web'in gücü evrenselliğindedir. Engelli olsun ya da olmasın herkes tarafından erişim, önemli bir özelliğidir."

Web erișilebilirliği, herhangi bir tarayıcıyı veya cihazı kullanan herhangi bir kullanıcının sanal ortamdaki içeriğe kolaylıkla erişebilmesini sağlamakla ilgilidir. Bu kapsamda internet ortamında içeriklerin kullanıcıların beklentilerine uygun olarak 
hazırlanmasına yönelik Web Erişilebilirlik Girişimi'nin (Web Accessibility InitiativeWAI) kılavuzu, Web İçeriği Erişilebilirlik Kılavuzu (Web Content Accessibility Guideline -WCAG) ve Dünya Çapında Web Konsorsiyumu Kılavuzu (World Wide Web Consortium- W3C) başta olmak üzere çok sayıda yönerge hazırlanmaktadır. Bu kılavuzlarla alanda çalışan tasarımcı, yazılımcı ve grafikerlerin farklı kullanıcıların kullanım beceri düzeyleri ve tercihleri hakkındaki farkındalıklarının sağlanması amaçlanmaktadır. Yine Web Erişilebilirlik Ölçüm Aracı (Web Accessibility Evaluation Tool) bir internet sitesinin kontrast ve renk ayarları bașta olmak üzere, tasarım ve içerikteki güçlüklerin kontrol edilebilmesine olanak sağlayarak; özellikle renk körleri ve görme güçlüğü çekenlerin içeriklere rahatça erişebilmelerini kolaylaştırmaktadır. Tüm bu belgelerde engelliliğin tanımı geniş tutularak; işitsel, görsel, fiziksel, bilişsel ve nörolojik kısıtı bulunan tüm kullanıcılara hitap edebilecek web içerikleri tasarlanmasına ilişkin kurallar geliştirilmektedir. Kılavuzlar mevcut tarayıcı teknolojileri ile ilgili bilgiler de içermektedir.

Friedman ve Breyen $(2007,208)$ mevcut web tasarım kllavuzlarında sıklıkla tekrarlanan tasarım önerilerini șöyle sıralamışlardır:

1. Metin ile birlikte resimler, işaretler ve semboller kullanın.

2. Açık ve basit bir metin kullanın.

3. Her sayfada uygun navigasyon ve tasarım kullanın.

4. Uygun konu ve bölüm başlıkları kullanın.

5. Ekranı okuyucu destekleyen tasarımlar oluşturun. Alternatif metin etiketleri kullanin.

6. Büyük yazı tiplerini tercih edin (En az 12pt veya 14pt).

7. Düzenli ve basit bir ekran planı kullanın.

8. Beyaz alanı koruyun: Geniş kenar boşlukları kullanın.

9. Web sitesi özelleştirilebilir ve kontrol edilebilir olmalıdır: yazı tipi boyutu, navigasyon yerleştirme (sağ, sol taraf) kontrast, ses.

10. Her sayfada çıkış, ana sayfa, yardım, sonraki sayfa tuşlarını kullanın.

11. Arial, Verdana, Helvetica ve Tahoma gibi sans serif (serifsiz) yazı tipleri kullanın.

12. Gezinme butonları açık, geniş ve tutarlı tutarı olmalıdır.

13. Madde imi yerine numaralı listeleri kullanın.

14. Farklı Web tarayıcıları için yazı tipi büyütme özelliğini destekleyin.

15. Kontrast için renk kullanın.

16. Otomatik araç ile okuma seviyesini kontrol edin.

17. Sağa yaslı metin kullanmayın.

18. Küçük harf kullanın, TAMAMI BÜYÜK HARF kullanmayın.

19. Metin için ses dosyaları sağlayın.

20. Sözcüklerin yüksek sesle okunması durumunda ses denetimi sağlayan araçlar ekleyin.

21. Kaybolduğunda kullanıcıların yönlerini kolayca bulabilmelerine yardımcı olmak için 'geri al', 'bir önceki menüye dön' gibi navigasyon yöntemlerini kullanın.

22. Bir kullanıcının eylemleri hakkında geri bildirim verin (ör., Doğru seçimleri onaylayın, kullanıcıları hatalara veya olası hatalara karşı uyarın).

Yeni teknolojiler maliyetsiz biçimde evrensel tasarıma uygun web içerikleri oluşturulmasına olanak sağlamasına karşın; internet ortamında birçok site ve mobil uygulama gerek hız baskısı, gerekse alanda çalışan profesyonellerin 
ihmali nedeniyle dezavantajlı kişilerin enformasyona ulaşmasını imkansız kılan erişilebilirlik engelleri ile tasarlanmaktadır. İçerik ve tasarımlardaki bu eksiklik ve yanlışları analiz eden çalışmalar, geniş bir biçimde erişilen bir web ortamına ve doğru bilgilendirilmiş bir kamuoyunun oluşmasına katkı sağlayacaktır.

\section{Yöntem ve Örneklem}

Bu araştırmada 16 Nisan 2017 Anayasa Değişikliği Referandumunda en çok tıklanan ana akım çevrimiçi gazetelerin kullandıkları haritaların evrensel tasarım ilkeleri bağlamında karşılaştırılması amaçlanmıştır. comScore'un haber ve bilgi sitelerini kapsayan 2 aylık (Temmuz-Ağustos 2017) raporuna göre; masaüstü bilgisayarlarda ve mobilde tekil kullanıcı sayısına göre Türkiye'nin internette en çok ziyaret edilen çevrimiçi haber siteleri örneklem olarak kabul edilmiştir.

Tablo 1: Masaüstü Bilgisayarlarda ve Mobil Telefonlarda Türkiye'nin Internette En Çok Ziyaret Edilen Çevrimiçi Haber Siteleri

\begin{tabular}{|c|c|c|c|c|c|}
\hline \multirow{2}{*}{ Çevrimiçi Gazete } & \multicolumn{2}{|c|}{$\begin{array}{c}\text { Masaüstü } \\
\text { (Tekil kullanıcı sayısı) } \\
\end{array}$} & \multirow{2}{*}{$\begin{array}{l}\text { Çevrimiçi } \\
\text { Gazete }\end{array}$} & \multicolumn{2}{|c|}{$\begin{array}{c}\text { Mobil } \\
\text { (Tekil kullanıcı sayısı) }\end{array}$} \\
\hline & $\begin{array}{c}\text { Temmuz } \\
2017\end{array}$ & $\begin{array}{l}\text { Ağustos } \\
2017\end{array}$ & & $\begin{array}{c}\text { Temmuz } \\
2017\end{array}$ & $\begin{array}{l}\text { Ağustos } \\
2017\end{array}$ \\
\hline $\begin{array}{l}\text { 1. Hürriyet } \\
\text { hurriyet.com.tr }\end{array}$ & 10.255 & 10.667 & $\begin{array}{l}\text { 1. Sözcü } \\
\text { sozcu.com.tr }\end{array}$ & 14.408 & 17.182 \\
\hline $\begin{array}{l}\text { 2. Milliyet } \\
\text { milliyet.com.tr }\end{array}$ & 9.398 & 9.754 & $\begin{array}{l}\text { 2. Milliyet } \\
\text { milliyet.com.tr }\end{array}$ & 15.472 & 16.557 \\
\hline $\begin{array}{l}\text { 3. Haber7 } \\
\text { haber7.com }\end{array}$ & 3.902 & 4.935 & $\begin{array}{l}\text { 3. Hürriyet } \\
\text { hurriyet.com.tr }\end{array}$ & 12.516 & 13.988 \\
\hline $\begin{array}{l}\text { 4. Sözcü } \\
\text { sozcu.com.tr }\end{array}$ & 4.337 & 4.803 & $\begin{array}{l}\text { 4. Habertürk } \\
\text { haberturk.com }\end{array}$ & 10.038 & 12.248 \\
\hline $\begin{array}{l}\text { 5. Sabah } \\
\text { sabah.com.tr }\end{array}$ & 4.280 & 4.233 & $\begin{array}{l}\text { 5. CNN Türk } \\
\text { cnnturk.com }\end{array}$ & 10.872 & 12.173 \\
\hline $\begin{array}{l}\text { 6. Haberler } \\
\text { haberler.com }\end{array}$ & 4.233 & 4.112 & $\begin{array}{l}\text { 6. Onedio } \\
\text { onedio.com }\end{array}$ & 6.890 & 7.646 \\
\hline $\begin{array}{l}\text { 7. Habertürk } \\
\text { haberturk.com }\end{array}$ & 3.723 & 3.963 & $\begin{array}{l}\text { 7. Gazete Vatan } \\
\text { gazetevatan.com }\end{array}$ & 4.131 & 4.545 \\
\hline $\begin{array}{l}\text { 8. Onedio } \\
\text { onedio.com }\end{array}$ & 3.721 & 3.653 & $\begin{array}{l}\text { 8. Akşam } \\
\text { aksam.com.tr }\end{array}$ & 3.653 & 2.985 \\
\hline $\begin{array}{l}\text { 9. CNN Türk } \\
\text { cnnturk.com }\end{array}$ & 3.642 & 3.536 & $\begin{array}{l}\text { 9. Posta } \\
\text { posta.com.tr }\end{array}$ & 2.833 & 2.933 \\
\hline $\begin{array}{l}\text { 10. Gazete Vatan } \\
\text { gazetevatan.com }\end{array}$ & 2.330 & 2.458 & $\begin{array}{l}\text { 10. Star } \\
\text { star.com.tr }\end{array}$ & 2.606 & 2.321 \\
\hline
\end{tabular}

Kaynak: Temmuz-Ağustos 2017,

Erişim: http://www.medyatava.com/haber/turkiyenin-en-cok-ziyaret-edilen-haber-siteleri-aciklandi_150072

Örneklemin popüler gazetelerle sınırlı tutulmasının nedeni, bu gazetelerin çalışan sayılarındaki fazlalık nedeniyle daha kapsamlı haritalar yayınlama imkânına sahip olmalarıdır. Seçilen gazetelerde referandum sonuçlarıyla ilgili yayınlanan dijital haritalar evrensel tasarıma uygunluklarına ilişkin olarak hazırlanan kodlama cetveline işlenerek, nicel içerik analizine tabi tutulmuştur.

Araştırmada referandum haberlerinde kullanılan dijital haritalar analiz edilerek, șu sorulara yanıt aranmıștır:

1. Çevrimiçi gazeteler dijital haritalarda hangi teknolojik özellikleri kullanmışlardır?

2. Çevrimiçi gazetelerin kullandığı dijital haritaların tasarımları ve içerikleri 
evrensel tasarım ilkelerine uygun mudur?

\section{Bulgular}

Bu başlık altında, Türkiye'de çok tıklanan çevrimiçi gazetelerin yayınladıkları dijital haritaların tasarımında ve içeriğinde evrensel tasarım ilkelerine uyup uymadıkları referandum haritaları özelinde analiz edilmiştir. Çevrimiçi gazetelerin evrensel tasarım duyarlılığı sorgulandığında, konunun yeterince önemsenmediği gözlenmektedir.

Tablo 2. Çok Tıklanan Çevrimiçi Gazetelerde Tasarımda Evrensel Illkeler (Çevrimiçi Gazeteler Alfabetik Sıraya Göre Dizilmiştir)

\begin{tabular}{|l|c|c|c|c|}
\hline \multirow{2}{*}{ Çevrimiçi Gazete } & \multicolumn{3}{|c|}{ Tasarımda Evrensel illkeler } \\
\cline { 2 - 5 } & Renk Seçeneği & Büyütme Seçeneği & Etkileşimli Arayüz & Ekran Okuyucu \\
\hline Akşam & Yok & Yok & Yok & Yok \\
\hline CNN Türk & Yok & Yok & Yok & Yok \\
\hline Gazete Vatan & Yok & Yok & Yok & Yok \\
\hline Haber 7 & Yok & Yok & Yok & Yok \\
\hline Haberler & Yok & Yok & Yok & Yok \\
\hline Habertürk & Yok & Yok & Yok & Yok \\
\hline Hürriyet & Yok & Yok & Yok & Yok \\
\hline Milliyet & Yok & Yok & Yok & Yok \\
\hline Onedio & Yok & Yok & Yok & Yok \\
\hline Posta & Yok & Yok & Yok & Yok \\
\hline Sabah & Yok & Yok & - & Yok \\
\hline Sözcü & - & - & Yok & Yok \\
\hline Star & Yok & Yok &
\end{tabular}

Sözcü gazetesi hariç, masaüstü ve mobil araçlarda en çok tıklanan tüm haber sitelerinin 16 Nisan 2017 Anayasa Değişikliği Referandumu sonuçlarını dijital haritalarla sundukları görülmektedir. Dijital haritalar, seçim sonuçlarını duyurmada başat anlatı türü olarak karşımıza çıkmaktadır.

Dijital haritalarda kullanıcılara farklı renk seçenekleri sunmak özellikle renk körleri ve görme güçlüğü yaşayan okurlar için kolaylık sağlamaktadır. Yaygın olarak "zoom" diye adlandırılan ekran büyütme seçeneği de benzer şekilde görme güçlügü yaşayan okurlar için elzemdir. Ekran okuyucu ise, özellikle görme engelli okurların enformasyona ulaşmasını kolaylaştıran bir teknolojidir. Evrensel tasarım ilkeleri kapsamında web erişilebilirliği ile ilgili kılavuzlarda vurgulanan tüm bu teknolojik özelliklerin, örneklem olarak seçilen çevrimiçi gazetelerde referandumla ilgili yayınlanan dijital haritaların hiçbirinde kullanılmadığı saptanmıştır. Başka bir anlatımla, teknolojik gelişmeler dezavantajlı grupların habere erişimini kolaylaştıracak uygulamalara imkan sağlasa da medya profesyonelleri bu uygulamaları kullanmamaktadır. Gelecekteki araştırmaların bu kullanım eksikliğin nedenlerine odaklanması önerilebilecektir. $\mathrm{Bu}$ haliyle dijital haritalar, basılı geleneksel haritalardan çok farklı bir görünüm arz etmemekte; daha yetkin bir kullanıcı deneyimi için müjdelenen teknolojik olanaklar okurlarla buluşmamaktadır. 
Tablo 3: Çok Tıklanan Çevrimiçi Gazetelerde Iç̧erikte Evrensel İlkeler (Çevrimiçi Gazeteler Alfabetik Sıraya Göre Sıralanmıştır)

\begin{tabular}{|l|c|c|c|c|c|}
\hline \multirow{2}{*}{ Çevrimiçi Gazete } & \multicolumn{5}{|c|}{ İcerikte Evrensel İkeler } \\
\cline { 2 - 6 } & Anlaşılır İçerik & $\begin{array}{c}\text { Geniş Kenar } \\
\text { Boşluğu }\end{array}$ & $\begin{array}{c}\text { Yazı Tipi } \\
\text { Serifli/Serifsiz }\end{array}$ & Harf Boyutu & $\begin{array}{c}\text { Harf Tasarımı } \\
\text { Büyük Harf/ } \\
\text { Küçük Harf }\end{array}$ \\
\hline Akşam & Kısmen & Var & Serifsiz & $12-14 \mathrm{px}$ & Büyük ve Küçük \\
\hline CNN Türk & Yok & Var & Serifsiz & $12-14 \mathrm{px}$ & Büyük \\
\hline Gazete Vatan & Yok & Var & Serifsiz & $12-14 \mathrm{px}$ & Küçük \\
\hline Haber 7 & Yok & Var & Serifsiz & $14-16 \mathrm{px}$ & Büyük \\
\hline Haberler & Yok & Var & Serifsiz & $14-16 \mathrm{px}$ & Küçük \\
\hline Habertürk & Yok & Var & Serifsiz & $12-14 \mathrm{px}$ & Büyük ve Küçük \\
\hline Hürriyet & Kısmen & Var & Serifsiz & $10-12 \mathrm{px}$ & Küçük \\
\hline Milliyet & Yok & Var & Serifsiz & $12-14 \mathrm{px}$ & Küçük \\
\hline Onedio & Yok & Yok & Serifsiz & $10-12 \mathrm{px}$ & Küçük \\
\hline Posta & Yok & Var & Serifsiz & $10-12 \mathrm{px}$ & Küçük \\
\hline Sabah & Yok & Var & Serifsiz & $14-16 \mathrm{px}$ & Büyük \\
\hline Sözcü & - & - & - & - & - \\
\hline Star & Kısmen & Var & Serifsiz & $14-16 \mathrm{px}$ & Büyük \\
\hline
\end{tabular}

Çevrimiçi gazetelerde yayınlanan dijital haritaların içerikleri incelendiğinde büyük bir bölümünün anlaşılır içeriğe sahip olmadığı gözlenmiştir. Harita üzerinde şehir adları yazılmamış, okurların yaşadıkları şehirleri harita üzerinde kendilerinin bularak anlatıyı kişiselleştirmesi beklenmiştir (Bkz. Görsel 1). Bu haliyle içerik dezavantajlı kullanıcılar başta olmak üzere tüm okurlar için oldukça karmaşıktır. Yalnızca Hürriyet ve Star gazetelerinin çevrimiçi haber sitelerinde şehir adlarının ilk üç harfi harita üzerinde gösterilmiş, okura kısmen rahatlık sağlanmıştır.

\section{ILLERE GÖRE REFERANDUM SONUÇLARI}

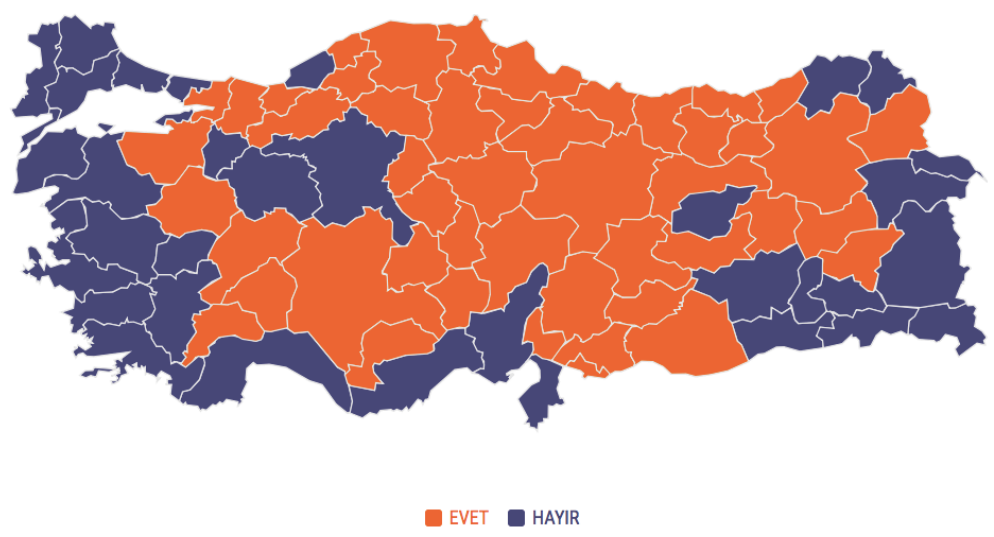

Görsel 1: Seçim sonuçlarını şehir adlarını yazmadan haritalaştıran gazete örneği Kaynak: https://www.sabah.com.tr/secim/16-nisan-2017-referandum/, Erişim: 01.05.2018

Web erişilebilirlik ilkelerine göre okumayı kolaylaştırmak için beyaz alanların mutlaka bırakılması gerekmektedir (World Wide Web Consortium/W3C, 2018; The Segue Creative Team, 2015). Yeterli genişlikte boşluklar (margin ve padding) sayfadaki bilgiye daha kolay erişim için elzemdir. Onedio internet sitesi haricinde tüm haber kuruluşlarının geniş kenar boşluğuna özen gösterdikleri, sayfayı 
reklama boğmadıkları ve bu anlamda temiz bir sayfa görünürlüğü sağladıkları söylenebilecektir.

Web erişilebilirliği ile ilgili ilkelerde yazı boyutunun 12px'den küçük olmaması, yazı fontunun serifsiz olması ve yazıların büyütülmesine olanak sağlayan eklentilerin (text zoom özelliği) sayfada kolayca bulunabilir bir yerde olması önerilmektedir. $\mathrm{Bu}$ ilkeler göz önüne alındığında çevrimiçi gazetelerin tamamı harita üzerindeki ve haritayı açıklayan metinlerde serifsiz harf kullanımına özen göstermiştir. Yine aynı internet sayfası üzerinde birden fazla yazı tipinin kullanılması kafa karıștırıcı olacağından tek bir yazı tipi tercih etmişlerdir. Harf boyutu konusunda Hürriyet, Onedio ve Posta gazeteleri özellikle harita üzerinde ekran büyütme seçeneğinin bulunmaması sebebiyle zor okunan puntolar kullanmışlardır. Diğer gazeteler ise, asgari uygunluk şartını sağlamakla birlikte, yine harita üzerinde ekran büyütme seçeneğinin bulunmaması sebebiyle tasarımda evrensel ilkelere uygun içerik tasarımı yapmamışlardır.

İnternetortamında tamamıbüyükharflerle metin oluşturmanın okumayıgüçleştirdiği de ilkelerde vurgulanan bir diğer konudur. Buna karşın gazetelerin bir bölümünün tamamı büyük harflerle dijital harita anlatısı oluşturdukları; bir bölümünün ise hem küçük hem de büyük harfe anlatıda yer verdikleri gözlenmektedir. Gazete Vatan, Haberler, Hürriyet, Milliyet, Onedio ve Posta gazetelerinin ise dijital harita haber anlatılarında yalnızca küçük harf tercih ederek, bu kurala uydukları gözlenmektedir.

\section{Sonuç ve Değerlendirme}

$\mathrm{Bu}$ araştırmada Türkiye'de çok tıklanan çevrimiçi gazetelerde yer alan dijital haritalarda web erişilebilirliği bağlamında evrensel tasarım ilkelerinin uygulanıp uygulanmadığı incelenmiştir. Dijital haritacılık teknolojileri daha iyi, bütünsel ve bağlamsal bilgiler içeren yetkin bir kullanıcı deneyimi potansiyeli taşısa da, çevrimiçi gazetelerde yer alan dijital haritalarda bu potansiyelin değerlendirilmediği gözlenmiştir.

Çevrimiçi gazetelerdeki harita anlatılarında geniş kenar boşluğu, serifsiz ve küçük harf kullanımı gibi içeriksel bazı ilkelere dikkat edilse bile; renk ve büyütme seçenekleri ile ekran okuyucu gibi özellikle engellilerin ve yaşlıların haber alma pratiklerini iyileştiren temel teknolojiler hiç kullanılmamaktadır. Dijital haber haritaları mevcut haliyle geleneksel basılı haritalardan büyük ölçüde farklı olmayıp, okur tatmini sağlayan yetkin bir medya anlatısı olarak karşımıza çıkmamaktadır.

$\mathrm{Bu}$ eksikliğin nedenlerini saptamak adına, gelecekteki çalıșmaların tasarım ve grafikle ilgilenen gazete çalışanlarının güncel kartografya teknikleri ve evrensel tasarım ilkeleri hakkındaki bilgi ve farkındalık düzeylerine odaklanması faydalı olacaktır. Engellilerin, çocukların ve yaşlıların web deneyimlerini kolaylaştıracak unsurların dijital haritalarda kullanımı geniş bir biçimde erişilen bir web ortamına ve doğru bilgilendirilmiş bir kamuoyunun oluşmasına katkı sağlayacaktır.

Öte yandan, büyük veri setleri dijital haritacılığın popülerleşmesine neden olurken, gazetecilerin öz yeteneklerine kartografinin de eklenmesini gerektirmektedir. $\mathrm{Bu}$ kapsamda gerek dijital haritacılık uygulamalarına yönelik konu ve derslerin programlara eklenmesine, gerekse medya okuryazarlığı eğitiminin yaratıcı veri okuryazarlığı ve eleștirel harita okunma becerilerinin geliştirilmesini de sağlayacak şekilde yeniden düzenlenmesine ihtiyaç duyulmaktadır. 


\section{Kaynakça}

Batuman, B. (2010). The Shape of the Nation: Visual Production of Nationalism Through Maps in Turkey. Political Geography, 29, 220-234.

Berendsen, M. E., Hamerlinck, J. D. ve Webster, G. R. (2018). Digital Story Mapping to Advance Educational Atlas Design and Enable Student Engagement. ISPRS International Journal of Geo-Information, 7, 125, 1-23.

Berners-Lee, T. (1997). W3C Leads Program to Make the Web Accessible for People with Disabilities (Press release). Erişim: https://www.w3.org/Press/WAILaunch.html

Brittain, K. D. (1995). Persons with Disabilities Can and Do Surf the Net! Colorado Libraries, 21, 17-19.

Center for Accessible Housing (1995). Accessible environments: Toward Universal Design. Raleigh: North Carolina State University

D'Ignazio, C. (2017). Creative Data Literacy: Bridging the Gap Between The DataHaves and Data-Have Nots. Information Design Journal, 23(1), 6-18.

D’Ignazio, C. ve Bhargava, R. (2016). DataBasic: Design Principles, Tools and Activities for Data Literacy Learners. The Journal of Community Informatics, 12(3), 83-107.

Del Casino, V. ve Stephen H. (2005). Beyond the Binaries: A Methodological Intervention for Interrogating Maps as Representational Practices. ACME: An International E-Journal for Critical Geographies, 4 (1), 36-56.

Demirci, A. ve Barut, Y. (2015). Türkiye'de Haber Kanallarında Harita Kullanımı. Marmara Coğrafya Dergisi, Sayı: 32, Temmuz, 1-21.

Dodge, M., Kitchin, R. ve Perkins, C. (2009). Thinking About Maps. Editör (Haz./Ed.). Dodge Martin, Kitchin Rob ve Chris Perkins. Rethinking Maps (s.1-25). New Frontiers in Cartographic Theory, London ve New York: Routledge.

Dorling, D. ve Fairbairn, D. (1997). Mapping: Ways of Representing the World. Harlow: Longman.

Friedman, M. G. ve Bryen, D. N. (2007). Web Accessibility Design Recommendations for People with Cognitive Disabilities. Technology and Disability, 19, 205-212.

Geller, T. (2007). Imaging the World: The State of Online Mapping. IEEE Computer Graphics and Applications, March-April, 27(2), 8-13.

Global Digital Map Market Report 2017-2021 (2017). Technavia.com, Erişim: 30 Haziran 2018, https://www.technavio.com/talk-to-us?report=Global+Digita l+Map+Market+2017-2021\&type=sample\&src=report

Harley, J. B. (1988). Maps, Knowledge and Power. Editör (Haz./Ed.). D. Cosgroveve S. Daniels. The Iconography of Landscape (s.277-312). Cambridge: Cambridge University Press.

Holmberg, M. O. ve Foote, K. E. (2008). Journalistic Cartography on the Web: A Comparison of Print and Online Maps in Seven Major American Newspapers. Editör (Haz./Ed.). Peterson M.P. International Perspectives on Maps and the Internet: Lecture Notes in Geoinformation and Cartography (s.323-340). Berlin ve Heidelberg: Springer. 
Kirsner, S. (1997). Web of Confusion. American Journalism Review. July, 19, 34-39.

Levin, P. (2016). The Digital Journalist's Toolbox: Mapping, IJNet: Internet Journalists' Network, July $21^{\text {st }} 2016$, Erişim: 30 Haziran 2018, https://ijnet.org/en/blog/ digital-journalist's-toolbox-mapping

Luchetta, S. (2017). Exploring The Literary Map: An analytical review of online literary mapping projects. Geography Compass, 1-17.

Mace, R. L. (1985). Universal Design: Barrier Free Environments for Everyone. Designers West, 33(1): 147-152.

Mace, R. L. (1991). The Accessible Housing Design File. Barrier Free Environments Incorporated.

Medzini, A. (2017). The Role Of Geographical Maps In Territorial Disputes Between Japan And Korea. European Journal of Geography, 8(1), 44 - 60.

Monmonier, M. (1989). Maps with the News: The Development of American Journalistic Cartography. Chicago: University of Chicago Press.

Monmonier, M. (2005). Lying with Maps, Statistical Science, 20(3), 215-222.

0’Beirne, Justin (2016). Cartography Comparison. Erişim: 30 Haziran 2018, https:// www.justinobeirne.com/cartography-comparison/\#back-note2

Quiquivix, L. (2014). Art of War, Art of Resistance: Palestinian Counter-Cartography on Google Earth. Annals of the Association of American Geographers: 104(3), 444-459.

Paciello, M. G. (1996). Making the Web Accessible for the Deaf, Hearing, and Mobility Impaired. Florida Libraries, 39, 83-91.

Robinson, A. C., Demšar, U., Moore, A. B., Buckley, A., Jiang, B., Field, K., Kraak, M.J., Camboim, S.P. ve Sluter, C.R. (2017). Geospatial Big Data and Cartography: Research Challenges and Opportunities for Making Maps that Matter. International Journal of Cartography, 3 (1), 32-60.

Salovaara, I. (2016). Participatory Maps: Digital Cartographies and The New Ecology of Journalism. Digital Journalism, 4(7), 827-837.

Schimak, G. , Havlik, D. ve Pielorz, J. Crowdsourcing in Crisis and Disaster Management - Challenges and Considerations. İçinde: Denzer R., Argent R.M., Schimak G., Hřebíček J. (ed.) Environmental Software Systems. Infrastructures, Services and Applications. ISESS 2015. IFIP Advances in Information and Communication Technology, vol 448. Springer, Cham, 56-70.

The Segue Creative Team (2015). Why Whitespace is so Important in Web Design. Segue Technologies, Erişim: 11 Temmuz 2018, https://www.seguetech.com/ whitespace-web-design/

Vujakovic, P. (2002). Mapping the War Zone: Cartography, Geopolitics and Security Discourse in the UK Press, Journalism Studies, 3(2), 187-202.

Wagner, J. (2015). Top 10 Mapping APIs: Google Maps, Microsoft Bing Maps and MapQuest. ProgrammableWeb, Erișim: 11 Temmuz 2018, https:// www.programmableweb.com/news/top-10-mapping-apis-google-mapsmicrosoft-bing-maps-and-mapquest/analysis/2015/02/23 
Web Accessibility Evaluation Tool (2018). Erişim: 11 Temmuz 2018, https://wave. webaim.org/

Web Accessibility Initiative (WAI) (2018). Erişim: 11 Temmuz 2018, https://www. w3.org/WAI/

Web Content Accessibility Guidelines (WCAG) (2018). Erişim: 11 Temmuz 2018, https://www.w3.org/WAI/standards-guidelines/wcag/

World Wide Web Consortium (W3C) (2018). Tips for Getting Started Designing for Web Accessibility. Erişim: 11 Temmuz 2018, https://www.w3.org/WAI/tips/ designing/ 
